\title{
Climate Change Sensitivity Evaluation from AIRS and IRIS Measurements
}

\author{
Yibo Jiang*a , Hartmut H. Aumann ${ }^{\mathrm{a}}$, Marie Wingyee_Lau ${ }^{\mathrm{b}}$, Yuk L. Yung ${ }^{\mathrm{b}}$ \\ ${ }^{a}$ Jet Propulsion Laboratory, Californian Institute of Technology, Pasadena, CA \\ ${ }^{b}$ Division of Geological and Planetary Sciences, Californian Institute of Technology, Pasadena, CA
}

\begin{abstract}
Outgoing longwave radiation (OLR) measurements over a long period from satellites provide valuable information for climate change. Due to the different coverage, spectral resolution and instrument sensitivities, the data comparisons between different satellites could be problematic and possible artifacts could be easily introduced. In this paper, we illustrate the method and procedures when we compare different satellite measurements by using the data taken by Infrared Interferometric Spectrometer (IRIS) in 1970 and by Atmospheric Infrared Sounder (AIRS) from 2002 to 2010. We use the spectra between $650 \mathrm{~cm}^{-1}$ and $1350 \mathrm{~cm}^{-1}$ for nadir view footprints in order to match the AIRS and IRIS measurements. Most of the possible sources of error or biases, which include the errors from spatial coverage, spectral resolution, spectra frequency shift due to the field of view, sea surface temperature uncertainty, clear sky determination, and spectra response function (SRF) symmetry, can be corrected. Using the correct SRF is extremely important when comparing spectra in the high slope spectral regions where possible large artifacts could be introduced.
\end{abstract}

Keywords: Climate Change, Sensitivity, AIRS, IRIS, Calibration, Ozone, $\mathrm{CO}_{2}, \mathrm{CH}_{4}$, Longwave Radiation, Modeling

\section{INTRODUCTION}

Satellite observations of the Earth atmosphere from space have been playing an important role in the study of climate change. The unbiased spatial and temporal coverage of polar satellites cannot be matched by in situ observations. The measurements of the spectrally resolved outgoing longwave radiation (OLR) show a strong link among climate state (Goody et al., 1998), sea surface temperature (SST) change, changes in greenhouse gases, characteristics of surface properties, cloud properties and distribution, and radiative forcing. Systematic measurements over a long period of time (over 10 years) are necessary for comparing climate change signals with climate modeling results. However, there are few satellite measurements that last more than a decade. Problems could arise and possible artifacts could be easily introduced, which could be misinterpreted as evidence of climate change, when measurements from difference satellites are compared, due to their different measurement configurations, implementations and data calibrations.

Clouds play an important role in climate change. Many satellites have been observing clouds for decades. By linking the spectrally resolved outgoing longwave radiation (OLR) to the climate state (Goody et al., 1998), changes in greenhouse gases, the characteristics of surface properties, cloud properties and distribution, and radiative forcing can be studied. Comparison of clear-sky spectra from IRIS (Prabhakara, 1988) and IMG (Interferometric Monitor for Greenhouse Gases) had been carried out by Harries et al. (2001) in order to single out the greenhouse gas effects. Brindley and Harries (2003) used the same data sets but included cloudy-sky spectra to study the cloud feedback.

The International Satellite Cloud Climatology Project (ISCCP) started analyzing cloud cover and cloud properties in 1983, and Rossow and Schiffer (1999) found a decrease of total cloud cover of 3.7\%/decade over tropical oceans, but no trends were found in high cloud cover. Wylie et al. (2005) analyzed the High Resolution Infrared Radiometer Sounder (HIRS) data from 1979 to 2001 by using CO2 slicing method to infer cloud amount and height. They found a small increase in total cloud cover of $1.4 \% /$ decade, and no trend in the high cloud cover over tropical oceans. However, both of their cloud retrieval methods rely heavily on modeling results.

Earth Observing Systems XVI, edited by James J. Butler, Xiaoxiong Xiong, Xingfa Gu, Proc. of SPIE Vol. 8153, 81531Z · (c) 2011 SPIE · CCC code: 0277-786X/11/\$18 · doi: 10.1117/12.892817 
In this paper, we will examine the spectral properties of the two data sets, and discuss the necessary steps and methods of processing the spectra before results from different satellite observations can be compared for climate signals.

\section{AIRS AND IRIS DATA SETS}

IRIS (Hanel, 1971) was a Fourier transform spectrometer (FTS). Two copies of IRIS flew on the NASA Nimbus 4 and 5 satellites in a $1100 \mathrm{~km}$ altitude sun-synchronous polar orbit. IRIS collected data from the nadir track between $400 \mathrm{~cm}^{-1}$ and $1600 \mathrm{~cm}^{-1}$ with $2.8 \mathrm{~cm}^{-1}$ resolution and $1.4 \mathrm{~cm}^{-1}$ sampling and $95 \mathrm{~km}$ diameter footprints from April 1970 until January 1971. AIRS (Aumann, 2003) is a grating spectrometer launched on the EOS-Aqua satellite in May 2002 and it measures spectra from $650 \mathrm{~cm}^{-1}$ to $2700 \mathrm{~cm}^{-1}$ by 2378 separate detector channels with $0.5-1.0 \mathrm{~cm}^{-1}$ spectral resolution. About 120 of the 2378 channels that either have failed or are too noisy are replaced using AIRS L1C algorithm (Elliott et al., 2008). AIRS scans to $\pm 49.5^{\circ}$ cross track as the satellite moves forwards taking 90 spectra each scan with an instantaneous field of view of $1.1^{\circ}$ in a row perpendicular to the direction of motion of the satellite. This results in a ground footprint of $13.5 \mathrm{~km}$ diameter at nadir. In this paper, we analyzed the spectra between $650 \mathrm{~cm}^{-1}$ and $1350 \mathrm{~cm}^{-1}$ for nadir view footprints which can be compared to IRIS's measurements. Table 1 shows the comparison of the properties of the IRIS and AIRS instruments.

Table1. Comparison of the properties of the IRIS and AIRS instruments

\begin{tabular}{|l|l|l|}
\hline Instrument & IRIS & AIRS \\
\hline Spectral Range $\left(\mathrm{cm}^{-1}\right)$ & $400-1600$ & $650-2700$ \\
\hline Spatial Field of View & $95 \mathrm{~km}$ diameter & $13.5 \mathrm{~km} \times 13.5 \mathrm{~km}$ (nadir) \\
\hline Spectral Resolution $\left(\mathrm{cm}^{-1}\right)$ & 2.8 & $0.4-1.0$ \\
\hline Total radiometric uncertainty $\left(\mathrm{mW} \mathrm{m}^{-2} \mathrm{sr}^{-1} \mathrm{~cm}^{-1}\right)$ & \pm 0.23 & $\pm(0.01-0.8)$ \\
\hline Equivalent brightness temperature uncertainty $(\mathrm{K})$ & \pm 0.15 & $\pm(0.00-0.45)$ \\
\hline
\end{tabular}

On average, there are about 94000 spectra each month for IRIS. Among those spectra, there are about 4500 clear sky measurements in the equatorial region between $20^{\circ}$ latitude south and $20^{\circ}$ latitude north. This number was approximately matched by sub-sampling the AIRS data. Both clear and cloudy data from day time and night time are used in this study. In addition, we do not use spectra for wavenumber larger than $1350 \mathrm{~cm}^{-1}$, since they are too noisy in the IRIS data. The year 2007 AIRS data is chosen to compare with the year 1970 IRIS data, as both years have similar Oceanic Nino Index (ONI) (NOAA Climate Prediction Center). Thus the cloud variability due to ENSO effects in both data sets should be equally accounted for.

While AIRS has excellent spectral and radiometric calibration (Strow et al., 2003; Aumann et al., 2003), little is known about IRIS in the literature on calibration validation. Harries et al. (2001) claim that under clear conditions the absolute accuracy of IRIS is about 0.5 to $0.75 \mathrm{~K}$ peak-peak, which is consistent with a noise equivalent temperature of $0.5 \mathrm{~K}$ as pointed out by Hanel et al. (1972). Aumann et al. (this issue) focused on the atmospheric window channel at $900 \mathrm{~cm}^{-1}$ in the tropical oceans to evaluate the absolute calibration accuracy of IRIS relative to AIRS. Their analysis shows that IRIS has a considerable day/night bias, about $0.7 \mathrm{~K}$ warmer during the day, $0.7 \mathrm{~K}$ colder at night, compared to AIRS. This is considerably larger than the absolute accuracy of $0.5 \mathrm{~K}$ stated by Harrries et al. (2001). However, any signal larger than about $1 \mathrm{~K}$ should be trustworthy.

\section{SPECTRAL AND RADIOMETRIC CALIBRATION OF SATELLITE MEASUREMENTS}

The different satellite measurements are calibrated according to their own requirements and specifications, which are not the same for different instrumentations. Extreme care must be taken when comparing different measurements in order to avoid any possible artifacts. AIRS instrument and IRIS instrument are 37 years apart, and their calibrations and errors are quite different as listed in Table 1. In this section, we will look into every possible aspect of calibrations that may affect the comparisons of satellite measurements and their application to the climate change study. Figure 1 shows the monthly 
averaged clear sky brightness temperature in May 2007 of AIRS and in May 1970 of IRIS. The method of processing this piece of monthly data is the topic of this paper and is discussed step by step in the following sessions. The channel locations of $\mathrm{CO}_{2}, \mathrm{O}_{3}, \mathrm{CH}_{4}$ are indicated in the plot, and their features are clearly shown in the 37-year difference of the spectra between AIRS and IRIS. The averaged $0.7 \mathrm{~K}$ difference in the window channels from 800 to $1000 \mathrm{~cm}^{-1}$ may be the bias in IRIS data sets.
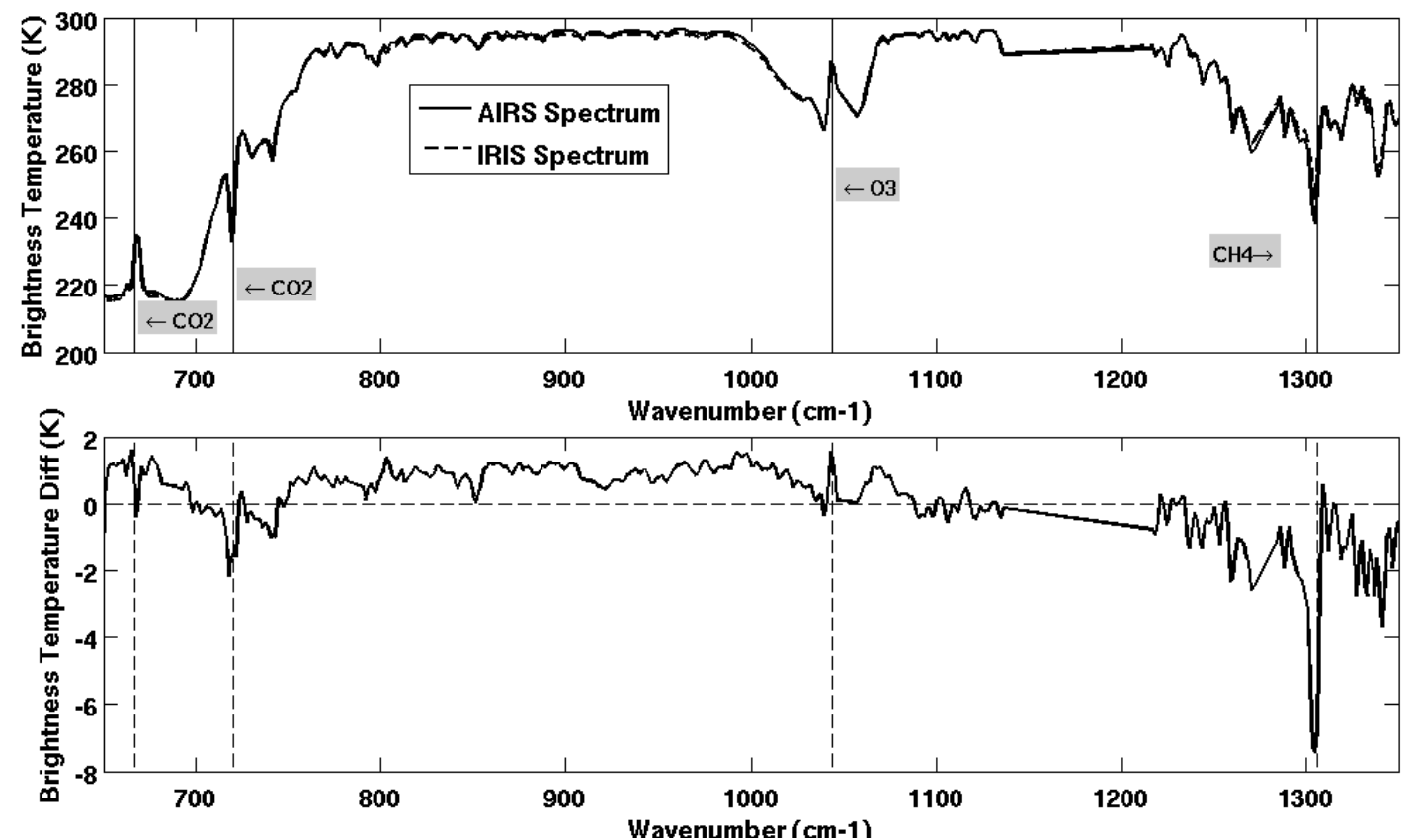

Figure 1. Monthly (May, 2007) averaged brightness temperature of AIRS and IRIS (top panel), and their differences (bottom panel).

\subsection{FIELD OF VIEW CORRECTION}

Previous studies have explored the impact of the spatial resolution on estimates of cloud fraction from both simulated and observed cloud fields. They indicate that cloud cover estimates are highly dependent on the instrument field of view (FOV) and cloud type. Here we use observational data to assess the impact of changes in the FOV on spectrally resolved brightness temperature as the first step in ascertaining whether a further comparison between different satellites would be worthwhile.

If the FOV of the two instruments differ by more than a factor of two, the higher spatial resolution data can be degraded with good accuracy to the lower spatial resolution. This is the case for the IRIS/AIRS comparison. IRIS is a nadir view satellite with a FOV of $95 \mathrm{~km}$, while AIRS scans cross track with nadir FOV of $13.5 \mathrm{~km}$. In order to downgrade AIRS spectra to IRIS spectra, and by assuming the IRIS instrument response function is flat so that each AIRS spectrum contributes equally, the AIRS spectra have to be averaged 6x6 pixels together around the center of the IRIS cell. In order to investigate the effects that different FOV could have on comparisons among different satellite measurements, we use the spatially more highly resolved AIRS data to model the effect of differing FOV.

Figure 2 shows the AIRS monthly averaged brightness temperature differences at two different FOVs $(9 \times 8$ and $5 \times 4$ pixels) as compared to the IRIS FOV which is $6 \times 6$ pixels for equivalent AIRS resolution. As pointed out by Brindley and Harries (2003), individual pixel or scene differences may be as large as $\pm 60 \mathrm{~K}$ when comparing different FOV satellite measurements depending on the cloud fraction in the scene. Here we show that in the case of the IRIS/AIRS comparison the differences could be as small as $0.02 \mathrm{~K}$ depending on the channels when averaged over a month. Because of this, the spatial resolution may play a minor role when doing the climate trend analysis. 


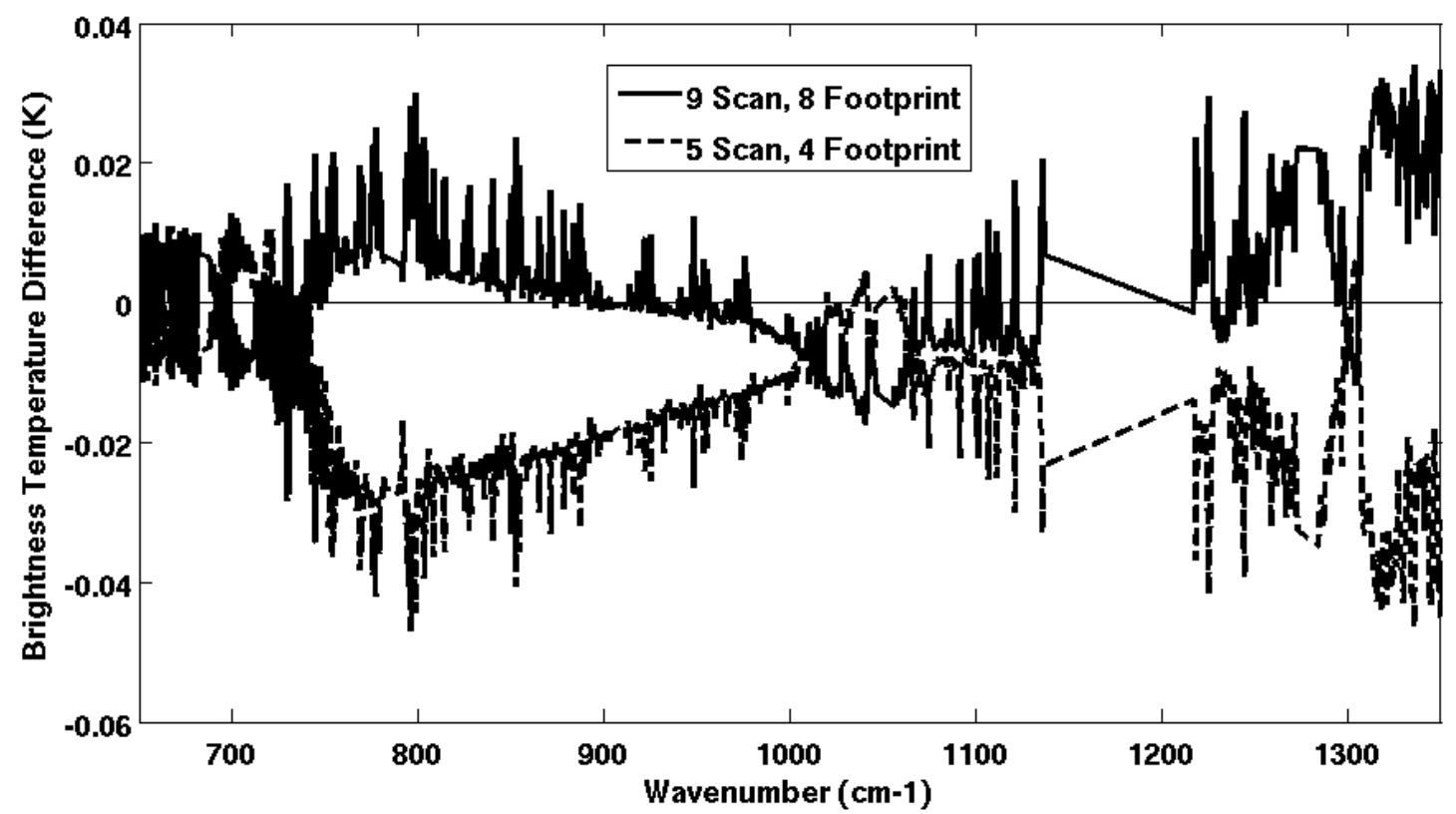

Figure 2. Monthly (May, 2007) averaged brightness temperature differences between different spatial sizes from AIRS instrument measurement. The solid line is the difference between $9 x 8$ spectrum averages as compared to 6x6 averages, and the dashed line is the difference between $5 \times 4$ spectrum averages as compared to $6 \times 6$ averages.

\subsection{SPECTRAL RESOLUTION CORRECTION}

When comparing the spectra from two different satellite measurements, the spectral resolution of one instrument often exceeds the other one. If the difference in spectral resolution is more than a factor of two, as is the case for the IRIS/AIRS comparison, the spectra of higher resolution can be degraded to the lower resolution spectra. Figure 3 shows the differences in brightness temperature as function of frequency at different levels of cloudiness, which we quantify by the cloud effects. We define cloud effect as the difference between brightness temperature at $900 \mathrm{~cm}^{-1}$ and sea surface temperature (SST) (the Extended Reconstruction Sea Surface Temperature analysis of v3b). The IRIS spectral resolution is about $2.8 \mathrm{~cm}^{-1}$. By fitting the AIRS spectra to IRIS spectra, we find that an IRIS spectral resolution of $3.2 \mathrm{~cm}^{-1}$ will give the best match to the IRIS spectra. We use higher spectral resolution data from AIRS to evaluate the error which is caused by the misinterpreted spectral resolution. The grey lines in Figure 3 represent the brightness temperature differences between spectral resolution of $3.2 \mathrm{~cm}^{-1}$ and spectral resolution $3.4 \mathrm{~cm}^{-1}$, while the black lines give the differences for spectral resolution of $3.0 \mathrm{~cm}^{-1}$. The plot shows for the clear sky (cloud effect $=0$ ) measurements with error about $\pm 0.1 \mathrm{~K}$ in the window channels, and increases to $\pm 1.0 \mathrm{~K}$ in the water channels. The error decreases in the cloudy measurements (cloud effect up to $-80 \mathrm{~K}$ ) because of the smearing effects of the cloud. The error in the $\mathrm{CO}_{2}$ stratospheric channel at $667.5 \mathrm{~cm}^{-1}$ is about $\pm 0.1 \mathrm{~K}$, and it stays almost the same for clear or cloudy spectra. 


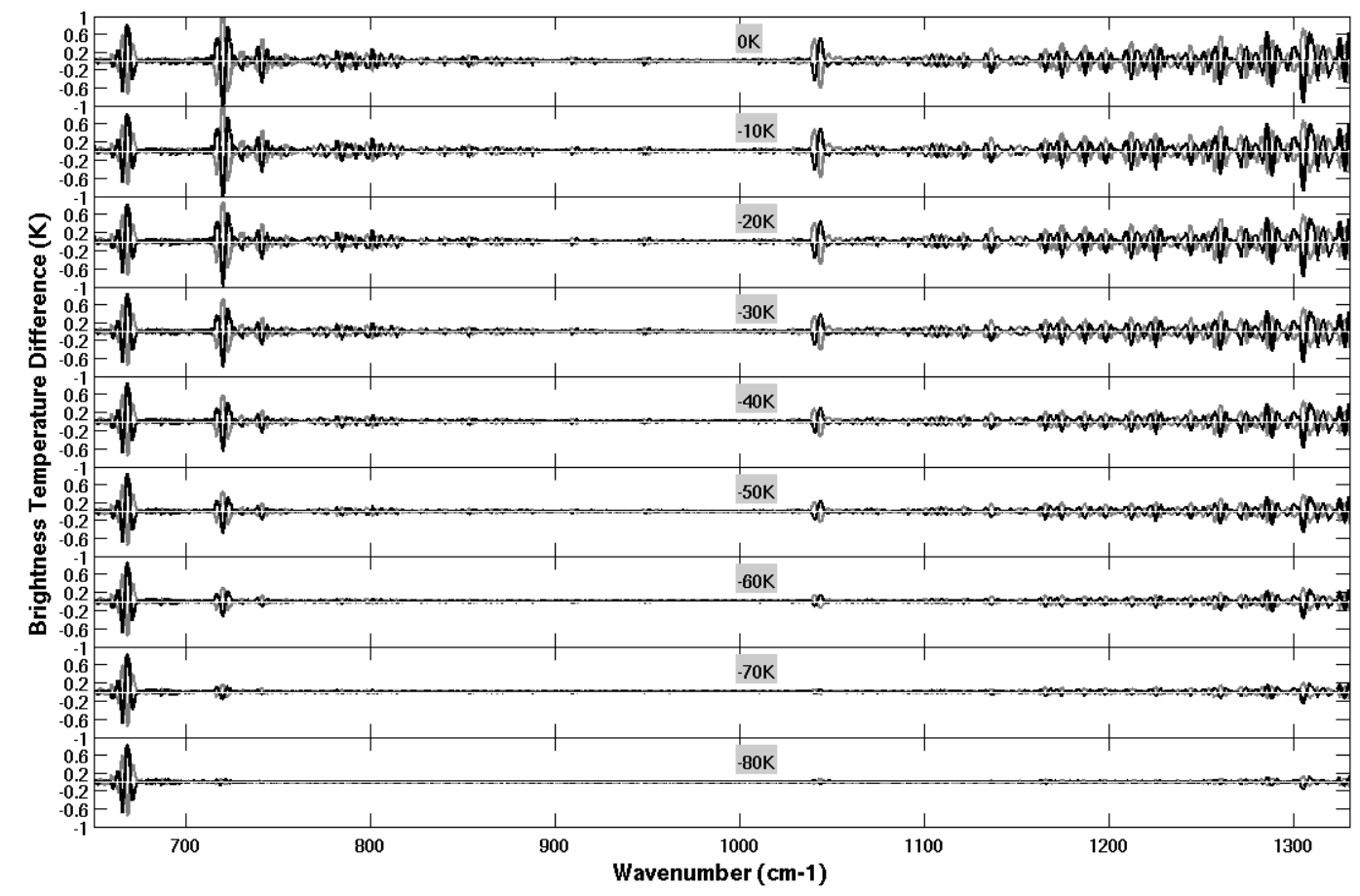

Figure 3. Monthly (May, 2007) averaged brightness temperature differences by assuming spectral resolution of $3.0 \mathrm{~cm}^{-1}$ and $3.4 \mathrm{~cm}^{-1}$ as compared to $3.2 \mathrm{~cm}^{-1}$. The grey line is for the $3.4 \mathrm{~cm}^{-1}$ resolution, and the black line is for the $3.0 \mathrm{~cm}^{-1}$ resolution.

\subsection{SPECTRAL SHIFT CORRECTION}

In addition, the wavenumber scales of the two different instruments are slightly different, owing to differing solid angles within the instruments. We found that we need to shift AIRS spectrum by $0.54 \mathrm{~cm}^{-1}$ at $1000 \mathrm{~cm}^{-1}$ channel in order to get the best fit to the IRIS spectrum. The shift is proportional to frequency for Fourier transform spectrometer. Our study indicates that this process needs to be performed extremely accurately in order to avoid artifacts appearing in the difference spectrum. 


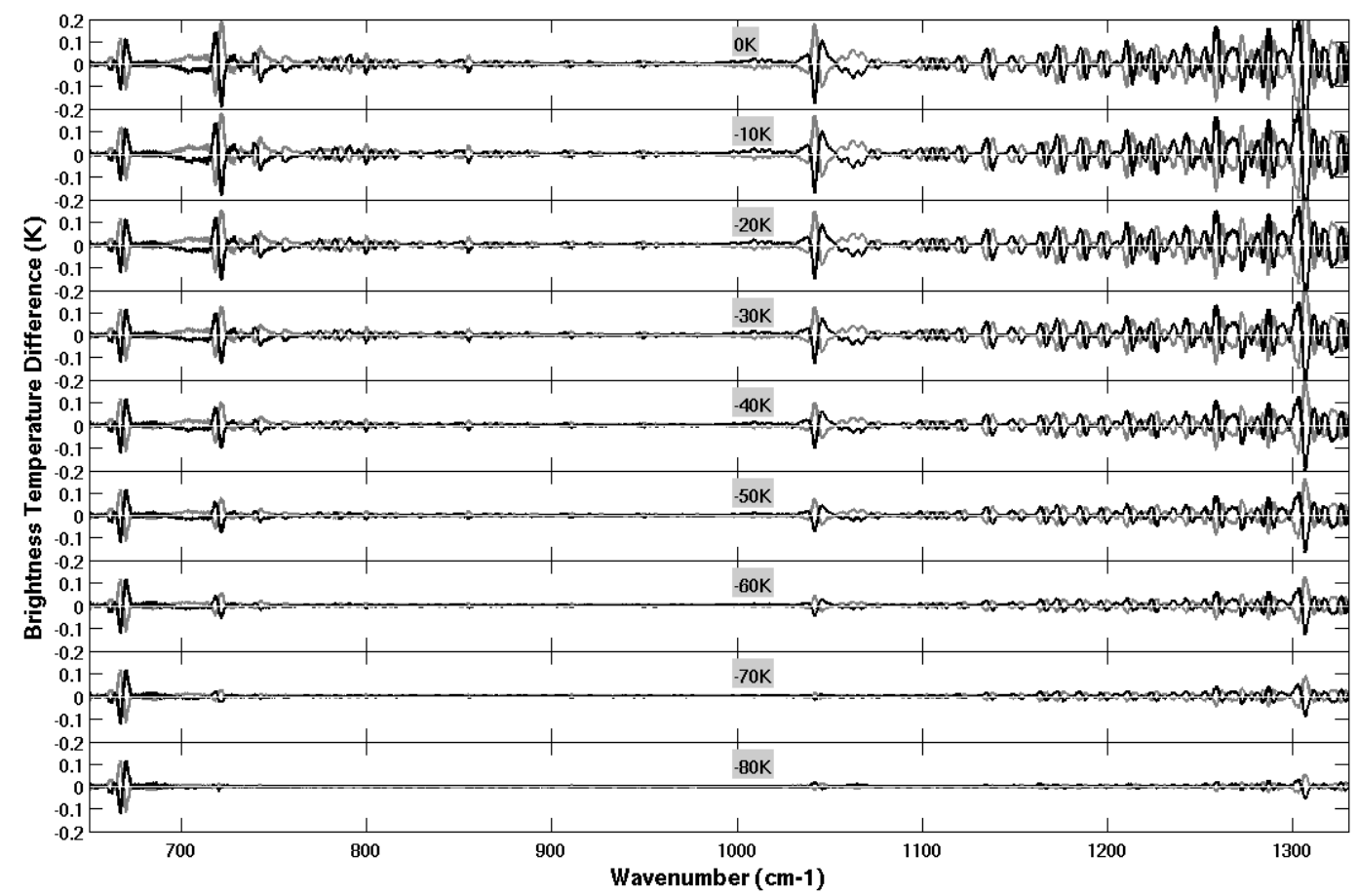

Figure 4. Monthly (May, 2007) averaged brightness temperature differences after shifting $0.52 \mathrm{~cm}^{-1}$ and $0.48 \mathrm{~cm}^{-1}$ as compared to $0.50 \mathrm{~cm}^{-1}$ shift at $1000 \mathrm{~cm}^{-1}$ channel from AIRS instrument measurement. The grey line is for the $0.52 \mathrm{~cm}^{-1}$ shift, and the black line is for the $0.48 \mathrm{~cm}^{-1}$ shift.

The error from spectral shift can be evaluated by shifting AIRS high spectral resolution spectrum by different amounts. Figure 4 indicates the monthly brightness temperature differences after shifting $\pm 4 \%$ or $\pm 0.02 \mathrm{~cm}^{-1}$ as compared to the optimized spectral shift. It shows the differences at different cloud effects; which are defined as in Figure 3 . The plot shows clearly that error is larger in the spectral range of the absorption features of major chemical species such as water vapor, $\mathrm{O}_{3}, \mathrm{CO}_{2}$, and $\mathrm{CH}_{4}$ in the atmosphere. The error is about $\pm 0.04 \mathrm{~K}$ in the window channels, and increases to $\pm 0.2 \sim 0.3 \mathrm{~K}$ in the other channels. As indicated in Figure 3, the error decreases in the cloudy measurements because of the smearing effects of the cloud. The error in the $\mathrm{CO}_{2}$ stratospheric channel at $667.5 \mathrm{~cm}^{-1}$ is about $\pm 0.1 \mathrm{~K}$, and it stays almost the same for clear or cloudy spectra.

\section{4. $\mathrm{O}_{3}, \mathrm{CH}_{4}, \mathrm{CO}_{2}$ AND $\mathrm{H}_{2} \mathrm{O}$ MODELING}

The Earth's outgoing longwave radiation spectrum indicates the greenhouse effect and the related radiative forcing of climate. In order to evaluate the absolute error from the measurements, the changes in the major greenhouse gases and scaled stratospheric cooling rate are then incorporated into the MODTRAN 5 model (Berk et al., 2005, 2008; Gail et al., 2007) in order to match the observed spectra. The atmospheric $\mathrm{CO}_{2}$ is set to be increased by $52 \mathrm{ppm}$ to match the current level, $\mathrm{CH}_{4}$ is increased by $30 \%, \mathrm{O}_{3}$ by $8 \%$ below the tropopause. The temperature profile is set to be the standard atmospheric temperature profile plus the one-fourth of the temperature change caused by $\mathrm{CO}_{2}$ doubling (Yung at al., 1997). The $\mathrm{H}_{2} \mathrm{O}$ profile is scaled according to the Clausius-Clapeyron relation.

Figure 5 shows that all of the principal features due to changes in $\mathrm{CO}_{2}, \mathrm{CH}_{4}, \mathrm{O}_{3}$, temperature and humidity are well modeled except the differences in the absolute quantity. The $\mathrm{CH}_{4}$ signal is about $4 \mathrm{~K}$ less deep in the model than the difference between AIRS and IRIS. MODTRAN is insufficient to produce the deep $\mathrm{CH}_{4}$ signal because of line mixing. The $\mathrm{O}_{3}$ signal is about $2 \mathrm{~K}$ smaller than the difference between AIRS and IRIS. The ozone absorption band centered at $1041 \mathrm{~cm}^{-1}$ is sensitive to lower stratospheric ozone level. However, at the time this paper is written, there is no agreement in the change in lower stratospheric ozone above the tropics. There is not even agreement on whether there is an increase or decrease (Solomon et. al, 2007). Hence the $2 \mathrm{~K}$ discrepancy may not be due a defect in MODTRAN but could be 
uncertainty in our ozone profile scaling and remaining frequency misalignment unsolved. The $\mathrm{CO}_{2}$ signal is comparable to that from AIRS minus IRIS. The discrepancy is within $0.5 \mathrm{~K}$ except for remaining frequency misalignment unsolved.

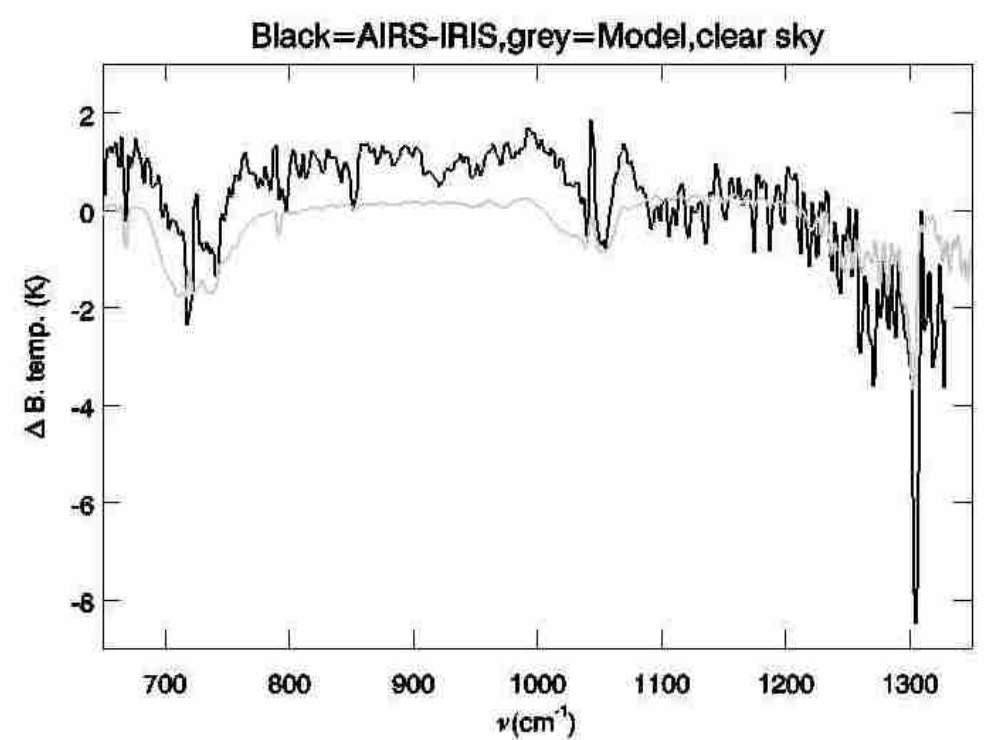

Figure 5. Monthly (May, 2007) averaged brightness temperature differences between AIRS and IRIS (black) and the modeled differences (grey) with $\mathrm{O}_{3}, \mathrm{CH}_{4}, \mathrm{CO}_{2}$ and $\mathrm{H}_{2} \mathrm{O}$ changed according to their trends.

\subsection{CLOUD CONTAMINATION EFFECTS}

There are two steps to follow in order to separate the clear and cloudy sky spectra as pointed out by Strabala et al. (1994). The first step is to compare the brightness temperature in window channel $900 \mathrm{~cm}^{-1}$ with the underlying sea surface temperature for the same time and location. If the difference exceeded a threshold, the spectrum is considered as being cloud contaminated. To be conservative, the threshold was set to be $5 \mathrm{~K}$ for both AIRS and IRIS spectra. The second step is to remove any residual spectral effects of cirrus clouds. But this step could remove too many spectra and there would not be a sufficient number of spectra left to make a effective comparison.

Here we have used more conservative threshold to identify the clear sky spectra. The spectra with brightness temperature at window channel $900 \mathrm{~cm}^{-1}$ less than $5 \mathrm{~K}$ as compared to the underlying sea surface temperature are labeled as clear. Even after filtering the cloudy spectra, there are always some spectra which are cloud contaminated. In this part of our study, we will investigate the error caused by the cloudy spectra. Figure 6 shows the clear spectra (black line) obtained from the difference between clear AIRS and clear IRIS spectra, and the modeled brightness temperature difference with $10 \%$ low cloud mixed into the modeled IRIS spectrum (grey line). It can be seen that in order to produce the negative signal of water vapor continuum, low cloud need to be mixed in the modeled IRIS spectrum. As it can be seen, the differences in brightness temperature are consistent for different cloudy heights. It indicates that the clear sky spectra in this process are well maintained and the error could be ignored. 


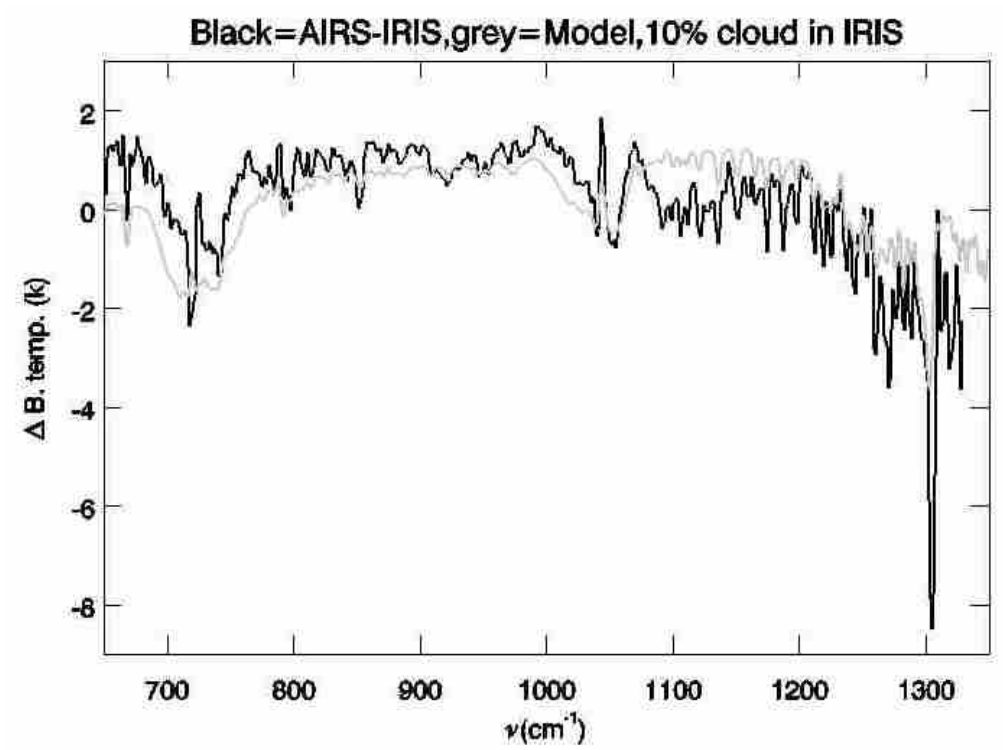

Figure 6. Modeled monthly (May, 2007) averaged brightness temperature differences with low cloud mixed into modeled IRIS as compared to the clear sky differences between AIRS and IRIS.

\subsection{SPECTRA TILT CORRECTION}

The slope of $1 \mathrm{~K}$ in the difference between AIRS and IRIS is seen in the 800 to $1000 \mathrm{~cm}^{-1}$ region, which is also observed by Harries et al. (2001). This could be caused by the small residual amounts of ice cloud, especially if composed of small crystals. Owning to the larger FOV, the IRIS spectra have a much higher possibility of being contaminated than AIRS. The change in the mean cirrus microphysical properties could also attribute the observed $1 \mathrm{~K}$ differences. There may have other factors affecting the slope as well, but we could not separate these effects. Practically, we have to tilt the noncontaminated spectrum such as AIRS to match the IRIS spectrum as shown in Figure 7. The spectral tilt did to the modeled AIRS spectrum was as follows: $(994$ - wavenumber $) * 0.004 \mathrm{~K}$ was added to the brightness temperature at every point.

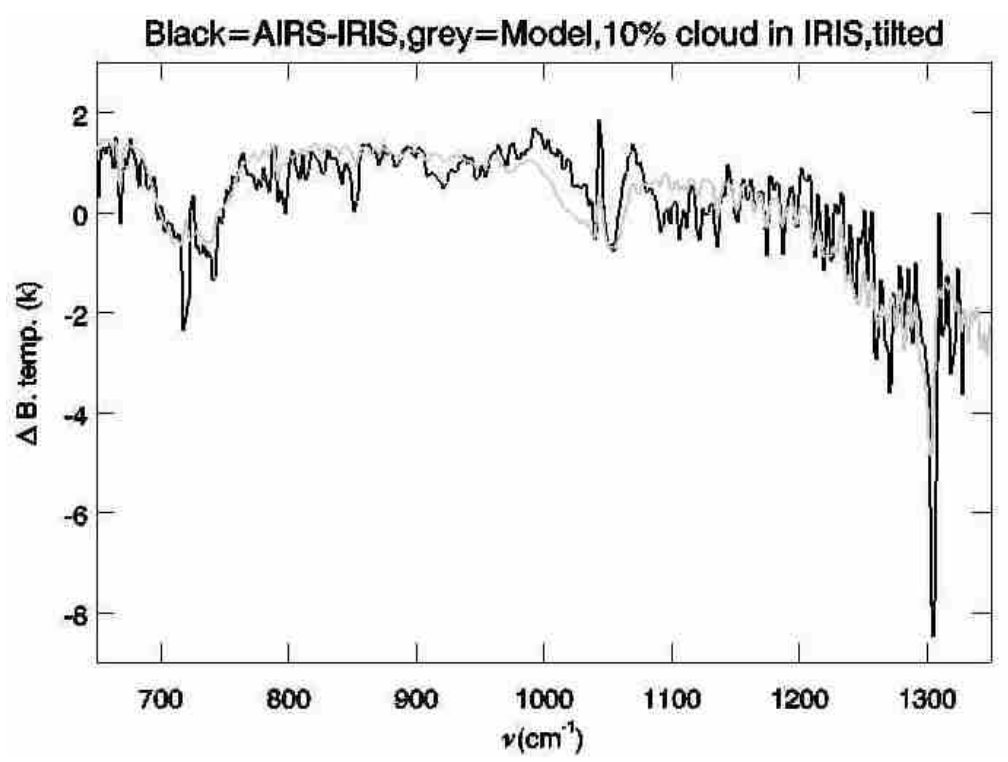


Figure 7. (Same as Figure 6) Modeled monthly (May, 2007) averaged brightness temperature differences with low cloud mixed into modeled IRIS as compared to the clear sky differences between AIRS and IRIS. The modeled spectral differences are tilted to match the measured differences.

We have finished the discussion on the first step of doing basic validations before we move on to any comparisons among different satellite measurements. As aforementioned, while AIRS measurements data are well validated (Strow et al., 2006; Aumann et al., 2006), IRIS data have to be well validated in several ways before they are used in the climate research, but little is published on IRIS validation. One way to compare and validate IRIS data set is to calculate the absorption features of various minor gases in the atmosphere that are well understood and to compare the results with the observations.

\section{RETRIEVAL AND PRELIMINARY VALIDATION OF KEY ATMOSPHERIC SPECIES}

After the calibration and correction of the spectra from AIRS and IRIS measurements, we are ready to retrieve the major chemical species in the atmosphere in order to validate some basic features, and give us confident when we use the data in the climate change study.

\section{1. $\mathrm{O}_{3}$}

We study the ozone channels centered at $1060.968 \mathrm{~cm}^{-1}$. It is well known that the high latitude stratospheric ozone is decreasing consistently since later 1970 due to the increasing anthropogenic chlorofluorocarbons in the atmosphere. The high levels of chlorine catalytically destroy the ozone over Antarctica every spring, causing over $60 \%$ depletion of total column ozone in October since 1970. Figure 8 depicts the monthly differences between AIRS (2007) and IRIS (1970) in brightness temperature at $70^{\circ}$ southern latitude. The AIRS ozone channels around $70^{\circ} \mathrm{S}$ show the maximum difference of about $4 \mathrm{~K}$ warmer than IRIS data can be reached in August, September and October, which is attributed to the known changes in ozone and surface temperature. From Figure 8, we can see the ozone hole builds up slowly in the southern winter and disappears fast in the southern spring. Model results from UMBC's model (Strow, personal communication) indicate that the ozone should decrease by $33 \%$ which is in good agreement with the Antarctic ozone hole observed, and that gives confidence in the quality of the IRIS data. However, we should note that the ozone signal is much larger than the $0.7 \mathrm{~K}$ absolute accuracy of the IRIS data.

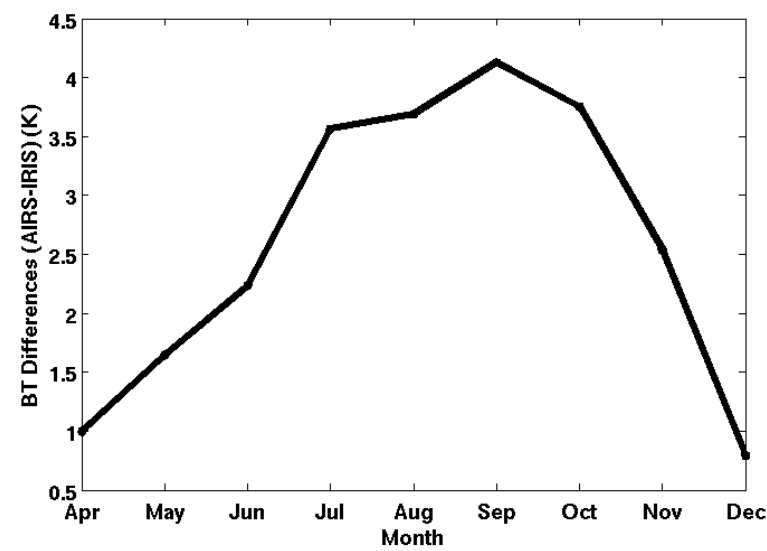

Figure 8. Monthly mean brightness temperature difference between AIRS in 2007 and IRIS in 1970 in $70^{\circ}$ southern latitude bin from April to December in the ozone channel $1060.968 \mathrm{~cm}^{-1}$.

\section{2. $\mathrm{CO}_{2}$}


Another chemical species to be used in the validation is the greenhouse gas $\mathrm{CO}_{2} \cdot \mathrm{CO}_{2}$ is well mixed in the troposphere, and the growth rate of $\mathrm{CO}_{2}$ is on average about $1.65 \mathrm{ppm}$ per year over the past 30 year period 1979-2008. The $\mathrm{CO}_{2}$ growth rate has on average increased over this period, averaging about $1.43 \mathrm{ppm}$ per year prior to 1995 and $1.91 \mathrm{ppm}$ per year thereafter. There is approximately $50 \mathrm{ppm}$ more $\mathrm{CO}_{2}$ in 2007 than IRIS measurement time 1970. This amount of $\mathrm{CO}_{2}$ increase can be estimated from the brightness temperature measurement in the $\mathrm{CO}_{2}$ channel $712 \mathrm{~cm}^{-1}$, which has a weighting function peak near $250 \mathrm{hPa}$. The detail comparisons of the $\mathrm{CO}_{2}$ amount in the atmosphere from IRIS and AIRS will not be discussed here.

\section{3. $\mathrm{CH}_{4}$}

A strong, negative Q-branch is observed at $1,304 \mathrm{~cm}^{-1}$ in the $\mathrm{CH}_{4}$ band, mainly due to the increases in tropospheric $\mathrm{CH}_{4}$ concentrations in the period between the observations, which causes emission from higher, colder layers of the troposphere. Negative-going lines due to $v 2$-band $\mathrm{H}_{2} \mathrm{O}$ absorption are seen between 1,200 and $1,400 \mathrm{~cm}^{-1}$. There is also evidence of weak features due to $\mathrm{CO}_{2}, \mathrm{CFC}-11$ and CFC-12 in the 700-1,000 $\mathrm{cm}^{-1}$ range. The detail comparisons of the $\mathrm{CH}_{4}$ amount in the atmosphere from IRIS and AIRS will not be discussed here.

\section{CONCLUSION}

We have shown the necessary steps to assure the correctness when using two satellite measurements to evaluate the climate change sensitivity. The sources of errors are summarized in Table 2. The major errors are from instrument system and $\mathrm{CH}_{4}$ modeling, which may be caused by spectral alignment or shift adjustment. Modeling of other greenhouse gases are also closely related to the SRF position. After all the corrections have been applied to the spectra, further validation is needed by showing the retrieval of major chemical components in the atmosphere.

Table 2: Summary of Sources of Uncertainty

\begin{tabular}{|l|l|}
\hline Error Sources & Uncertainty (K) \\
\hline Instrument System & \pm 0.50 \\
\hline Field of View & \pm 0.02 \\
\hline Spectral Shift & \pm 0.05 \\
\hline Spectral Resolution & \pm 0.10 \\
\hline $\mathrm{CO}_{2}$ (troposphere) & \pm 0.30 \\
\hline $\mathrm{O}_{3}$ (troposphere) & \pm 0.50 \\
\hline $\mathrm{CH}_{4}$ (troposphere) & \pm 4.00 \\
\hline $\mathrm{H}_{2} \mathrm{O}$ (troposphere) & \pm 0.50 \\
\hline Spectral Tilt Adjustment & \pm 0.20 \\
\hline
\end{tabular}

\section{ACKNOWLEDGMENTS}

This work was carried out at Caltech's Jet Propulsion Laboratory under contract with NASA.

\section{REFERENCES}

[1] Alexander Berk, Gail P. Anderson, Prabhat K. Acharya, Lawrence S. Bernstein, Leon Muratov, Jamine Lee, Marsha Fox, Steve M. Adler-Golden, James H. Chetwynd, Michael L. Hoke, Ronald B. Lockwood, James A. Gardner, Thomas W. Cooley, Christoph C. Borel and Paul E. Lewis, "MODTRAN 5: a reformulated atmospheric band model with auxiliary species and practical multiple scattering options: update", Proc. SPIE 5806, 662, 
doi:10.1117/12.606026 (2005).

[2] Aumann, H.H., et al., "AIRS/AMSU/HSB on the Aqua Mission: Design, Science Objectives, Data Products, and Processing Systems," IEEE TRANSACTIONS ON GEOSCIENCE AND REMOTE SENSING, 41, 253-264 (2003).

[3] Aumann, H.H., Davig Gregorich and Steve Gaiser, "AIRS hyper-spectral measurements for climate research: Carbon Dioxide and nitrous oxide effects," Geophys. Res. Lett., 32, L05806, doi:10.1029/2004GL021784 (2005).

[4] Aumann, H.H., S. Broberg, D. Elliott, G. Gaiser, and D. Gregorich, "Three years of Atmospheric Infrared Sounder radiometric calibration validation using sea surface temperatures," J. Geophys. Res., 111, D16S90, doi:10.1029/2005JD006822 (2006).

[5] Berk, A., Anderson, G.P., Acharya, P.K., and Shettle, E.P, "MODTRAN®5.2.0.0 User's Manual”, Spectral Sciences, Inc, Burlington, MA, Air Force Research Laboratory, Hanscom AFB, MA (2008).

[6] Brindley, H.E., and J.E. Harries., "The impact of instrument field of view on measurements of cloudy-sky spectral radiances from space: application to IRIS and IMG," J. Quant. Spec. Rad. Trans., 78, 341-352 (2003).

[7] Elliott, D. A., H. H. Aumann, Y. Jiang, and S. E. Broberg, "Level 1C spectra from the Atmospheric Infrared Sounder (AIRS), " Earth Observing Systems XIII, Edited by Butler, James J., Xiong, Jack, Proceedings of the SPIE, Volume 7081, pp. 70810L-70810L-9 (2008).

[8] Gail P. Anderson, Alexander Berk, James H. Chetwynd, Jr., Jerald Harder, Juan M. Fontenla, Eric P. Shettle, Roger Saunders, Hilary E. Snell, Peter Pilewskie, Bruce C. Kindel, James A. Gardner, Michael L. Hoke, Gerald W. Felde, Ronald B. Lockwood and Prabhat K. Acharya, "Using the MODTRAN5 radiative transfer algorithm with NASA satellite data: AIRS and SORCE", Proc. SPIE 6565, 65651O; doi:10.1117/12.721184, (2007).

[9] Goody, R., J. Anderson, and G. North, "Testing Climate Models: An Approach,” Bull. Amer. Meteor. Soc, Vol. 79, No. 11 (1998).

[10] Hanel, R.A., B. Schlachman, D. Rogers, and D. Vanous, "Nimbus 4 Michelson Interferometer," Applied Optics, 10, no.6, 1376-1382, (1971).

[11] Hanel, R.A., et al., "The Nimbus 4 infrared spectroscopy Experiment 1. Calibrated thermal emission spectra," $J$. Geophys. Res., 77, 2629 (1972).

[12] Harries et al., "Increases in greenhouse forcing infered from the outgoing longwave radiation spectra of the Earth in 1970 and 1997," Nature, 410,355-357 (2001).

[13] Prabhakara C., R. S. Fraser, G. Dalu, M.-L. C. Wu, and R. J. Curran, "Thin cirrus clouds: Seasonal distribution over oceans deduced from Nimbus-4 IRIS," J. Appl. Meteor, 27, 379-399 (1988).

[14] Rossow and Schiffer, "Advances in Understanding Clouds from ISCCP", Bull. Amer. Meteor. Soc., 80, 2261-2287 (1999).

[15] Smith, T.M., R.W. Reynolds, Thomas C. Peterson, and Jay Lawrimore, Improvements to NOAA's Historical Merged Land-Ocean Surface Temperature Analysis (1880-2006). J. of Climate, 21, 2283-2296 (2008).

[16] Solomon, S., D. Qin, M. Manning, Z. Chen, M. Marquis, K.B. Averyt, M. Tignor and H.L. Miller (eds.), Contribution of Working Group I to the Fourth Assessment Report of the Intergovernmental Panel on Climate Change. Cambridge University Press (2007)

[17] Strabala, K., S. Ackerman, and W. Menzel, "Cloud properties inferred from 8-12 $\mu \mathrm{m}$ data," J. Appl. Meteorol., 33, 212-229 (1994).

[18] Strow, L.L., S.E. Hannon, M. Weiler, K. Overoye, S.L. Gaiser, and H.H. Aumann, "Prelaunch Spectral Calibration of the Atmospheric Infrared Sounder (AIRS)," IEEE TRANSACTIONS ON GEOSCIENCE AND REMOTE SENSING, 41, 274-286 (2003).

[19] Strow, L.L., S.E. Hannon, S. De-Souza Machado, H. E. Motteler, and D. C, Tobin, "Validation of the Atmospheric Infrared Sounder radiative transfer algorithm," J. Geophys. Res., 111, D09S06, doi:10.1029/2005JD006146 (2006).

[20] Wylie, D., D.L. Jackson, W.P. Menzel, and J.J. Bates, Trends in global cloud cover in two decades of HIRS observations, J. of Climate, 18, 3021-3031 (2005).

[21] Yung, Y. L., Y. Jiang, H. Liao, and M. F. Gerstell, "Enhanced UV Penetration due to Ozone Cross Section Changes Induced by CO2 doubling," J. Geophys. Res., 24, 3229-3231. (1997). 